\title{
PENGARUH IKLIM ORGANISASI DAN SISTEM REWARD TERHADAP KEPUASAN KERJA DAN KOMITMEN ORGANISASIONAL PADA CV. WIRACANA
}

\author{
I Kadek Mahendra ${ }^{1}$ \\ Made Subudi ${ }^{2}$ \\ ${ }^{1,2}$ Fakultas Ekonomi dan Bisnis Universitas Udayana, Bali, Indonesia \\ Email: kadekmahendra21@gmail.com
}

\begin{abstract}
ABSTRAK
Persaingan yang terjadi antar perusahaan pada era globalisasi ini menuntut perusahaan untuk terus melakukan peningkatan atau sebuah perubahan agar tetap bisa bersaing. Tujuan penelitian adalah menganalisis pengaruh iklim organisasi dan sistem reward terhadap kepuasan kerja dan komitmen organisasional. Sampel ditentukan sebanyak 86 orang dengan teknik sampling jenuh. Pengumpulan data dilakukan dengan menyebar kuesioner secara langsung kepada karyawan CV. Wiracana dan dianalisis menggunakan statistik dekriptif rata-rata hitung serta statistik deskriptif berupa uji asumsi klasik dan analisis jalur. Hasil analisis data menunjukkan bahwa variabel iklim organisasi dan sistem reward berpengaruh positif dan signifikan terhadap kepuasan kerja. Iklim organisasi, sistem reward dan kepuasan kerja berpengaruh positif dan signifikan terhadap komitmen organisasional pada CV.Wiracana.
\end{abstract}

Kata kunci : iklim organisasi, sistem reward, kepuasan kerja, komitmen organisasi.

\begin{abstract}
Competition that occurs between companies in the era of globalization requires companies to continue to make improvements or a change in order to remain competitive. The purpose of the study was to analyze the influence of organizational climate and reward system on job satisfaction and organizational commitment. The sample was determined by 86 people with saturated sampling techniques. Data collection is done by distributing questionnaires directly to CV employees. Wiracana and analyzed using calculative descriptive statistics and descriptive statistics in the form of classic assumption tests and path analysis. The results of data analysis show that organizational climate variables and reward systems have a positive and significant effect on job satisfaction. The organizational climate, reward system and job satisfaction have a positive and significant effect on organizational commitment on CV.Wiracana.
\end{abstract}

Keyword: organizational climate, reward system, job satisfaction, organizational commitment. 
I Kadek Mahendra, dan Made Subudi. Pengaruh Iklim Organisasi dan Sistem Reward....

\section{PENDAHULUAN}

Persaingan yang terjadi antar perusahaan pada era globalisasi ini menuntut perusahaan untuk terus melakukan peningkatan pengelolaan sumber daya manusia. Mengelola sumber daya manusia tidaklah mudah, sebab manusia mempunyai karakteristik yang berbeda - beda. Keberhasilan perusahaan dalam mengelola sumber daya manusia akan meningkatkan efektivitas dan efisiensi. Dessler (2016:3) menyatakan manajemen sdm adalah proses agar mendapatkan, melatih, menilai serta memberikan kompensasi pegawai, juga agar mengurus relasi karyawan mereka, kesehatan juga keselamatan karyawan, dan berbagai hal yang memiliki hubungan dengan keadilan.

CV. Wiracana yaitu perusahan yang bergerak pada bidang kerajinan seperti kipas tangan yang berlokasi di J1. Raya Sesetan, G3. Merpati No. 3, Denpasar Selatan. Produk CV. Wiracana berhasil menjelajahi pasar internasional seperti Spanyol, Jepang, Amerika, Meksiko, Fiji, Perancis, Jerman, Australia, Italia dan negara - negara lain di Asia Tenggara. CV. Wiracana tetap melakukan inovasi terhadap kualitas produk sebagai satu-satunya industri kerajinan kipas di Bali yang menggabungkan Hi-tech dengan buatan tangan. Dengan konteks menjaga kualitas dari produk agar tetap terjaga, maka peran karyawan sangat penting dalam memenuhi kualitas yang dituju oleh Wiracana.

$\mathrm{CV}$. Wiracana membuka toko cabang baru yang berfungsi sebagai galeri produk di tahun 2018. Cabang terbaru tersebut dibuka di Jalan By Pass Ngurah Rai no. 27, Tohpati, Denpasar Bali. Ekspansi yang dilakukan perusahaan ini menyebabkan beberapa staf ahli yang dulunya bertugas di kantor pusat dipindahkan ke cabang. Pemindahan tugas ini membuat adanya ketidak puasan yang timbul pada karyawan yang dipindahtugaskan tersebut. Ketidak puasan yang dirasakan karyawan tersebut dikarenakan pindah tempat kerja yang menyebabkan semakin jauhnya jarak yang harus ditempuhnya untuk berangkat kerja tanpa adanya kenaikan gaji ataupun insentif lainnya.

Hasil observasi pada CV. Wiracana, terdapat masalah mengenai rendahnya kepuasan kerja dan komitmen terhadap organisasi. Rendahnya tingkat kepuasan kerja ini ditimbulkan oleh adanya ekspansi yang baru-baru ini dilaksanakan oleh perusahaan. Karyawan yang memiliki tingkat kepuasan yang rendah dan tidak berkomitmen terhadap organisasi akan menghambat tujuan dari CV. Wiracana karena rendahnya kepuasan kerja yang dirasakan serta rendahnya komitmen terhadap organisasi yang dimiliki oleh setiap karyawan berarti karyawan merasa kurang diperhatikan dalam bekerja serta tidak memiliki loyalitas pada organisasi. Data awal yang didapatkan menunjukkan jumlah karyawan pada $\mathrm{CV}$. Wiracana yang berjumlah 86 orang. Diantaranya terdari dari Marketing 1 orang, Accounting 2 orang, Purchasing 4 orang, Design Grafis 3 orang, Pengawas I s.d VI 6 orang, House Keeping 5 orang, Bagian Produksi 57 orang.

Indikasi rendahnya tingkat kepuasan kerja dan komitmen organisasional pada karyawan CV.Wiracana dapat ditinjau dari tingkat perputaran karyawan yang menunjukkan angka yang tinggi. Gillies (1989) dalam (Intan, Kusuma, \& Mujiati, 2017) menyatakan bahwa perputaran karyawan dikatakan tinggi apabila lebih dari 10 persen per tahun. Data turnover karyawan CV. Wiracana tahun 2015-2017 dapat dilihat pada Tabel 1. 
Tabel 1.

Data Turnover Karyawan CV.Wiracana Tahun 2015-2017

\begin{tabular}{|c|c|c|c|c|c|c|}
\hline Bulan & $\begin{array}{l}\text { Awal } \\
\text { tahun } \\
\text { (orang) } \\
\text { (1) }\end{array}$ & $\begin{array}{c}\text { Akhir } \\
\text { tahun } \\
\text { (orang) } \\
(2)\end{array}$ & $\begin{array}{c}\text { Rata-rata } \\
\quad(3)= \\
(1)+(2): 2\end{array}$ & $\begin{array}{c}\text { Karyawan } \\
\text { masuk } \\
\text { (orang) } \\
(4)\end{array}$ & $\begin{array}{c}\text { Karyawan } \\
\text { keluar } \\
\text { (orang) } \\
(5)\end{array}$ & $\begin{array}{c}\text { Karyawan } \\
\text { keluar }(\%) \\
(6)= \\
(5):(3) \times 100 \\
\%\end{array}$ \\
\hline 2015 & 107 & 102 & 104,5 & 9 & 14 & $13,40 \%$ \\
\hline 2016 & 102 & 94 & 98 & 7 & 15 & $15,31 \%$ \\
\hline 2017 & 94 & 86 & 90 & 4 & 12 & $13,33 \%$ \\
\hline
\end{tabular}

Sumber: Data Diolah, 2018

Tabel 1. menunjukkan tingkat turnover karyawan CV. Wiracana paling tinggi pada tahun 2016 sebesar 15,31\%, kondisi ini perlu mendapat perhatian dari manajemen karena tingginya turnover karyawan yang mengindikasikan rendahnya tingkat kepuasan yang dirasakan karyawan dalam bekerja, serta berpindahnya karyawan ke organisasi lain mengindikasikan rendahnya komitmen organisasional pada organisasi. Suryanatha menyatakan rendahnya komitmen didalam suatu organisasi menunjukkan kurang tanggung jawab seseorang karyawan dalam melaksanakan pekerjaannya (Suryanatha \& Ardana, 2014). Mathis et al. (2001) menyatakan komitmen organisasional memberikan perhatian dengan spesial untuk kelanjutan factor-faktor komitmen yang memberi saran keputusan itu agar tetap ataupun pergi dari perusahaan yang untuk diakhir memberi gambaran didalam statistik ketidakhadiran serta turnover tenaga kerja.

Komitmen untuk perusahaan adalah sikap yang dipunyai oleh pegawai serta menuju di perusahaan tempat mereka kerja, memiliki hubungan dengan kemauan mendapatkan nilai juga tujuan daripada perusahaan, kesetiaan juga mau atau tidaknya pegawai berkorban untuk tercapainya tujuan perusahaan, dan mempunyai rasa ingin agar tetap jadi bagian daripada perusahaan (Tommy S Suyasa, Coawanta, 2004). Menurut (Made \& Puspitawati, 2014) komitmen organisasi adalah sikap dimiliki karyawan untuk tetap loyal terhadap perusahaan dan bersedia untuk tetap bekerja sebaik mungkin demi tercapainya tujuan organisasi. Karyawan yang memiliki komitmen yang tinggi terhadap organisasi dan cenderung ingin setia, berkorban, berkontribusi dan menetap pada organisasi ditempat ia bekerja karena merasa nyaman dan puas. Komitmen organisasional bisa diukur melalui indikator seperti 1) komitmen afektif; 2) komitmen kontinyu; 3) komitmen normatif. Wawancara awal terhadap karyawan $\mathrm{CV}$. Wiracana ditemukan masalah pada komitmen yang dimiliki oleh karyawan terhadap perusahaannya masih rendah, hal ini dibuktikan dengan hasil awal wawancara 20 karyawan CV. Wiracana yang dipilih secara acak dari bagian marketing, accounting, purchasing, desain grafis, pengawas I-VI, housekeeping, bagian produksi didapatkan hasil bahwa 16 dari 20 karyawan menyatakan bahwa mereka kurang berkomitmen terhadap perusahaan yang menyebabkan rendahnya komitmen yang ada pada karyawan CV Wiracana terhadap perusahaan. Candra dan Riana (2017) dalam penelitiannya di Hotel Blue Point menyatakan bahwa tingginya kepuasan kerja yang diterima oleh karyawan akan berbanding lurus dengan komitmen mereka terhadap perusahaan.

Penelitian yang dilakukan oleh Hayes pada tahun 2010 memberikan petunjuk bahwasannya kepuasan kerja serta sebuah hal yang rumit serta multifaktorial kejadian, dimana kolaborasi diantara pribadi, atasan juga orang lain adalah hal-hal 
I Kadek Mahendra, dan Made Subudi. Pengaruh Iklim Organisasi dan Sistem Reward....

vital agar memberikan kepuasan pegawai dengan kerjaannya (Hayes, Bonner, \& Pryor, 2010). Menurut (Teck-Hong \& Waheed, 2011) kepuasan kerja merupakan faktor penting yang menentukan kesuksesan suatu organisasi. Kepuasan akan pekerjaan yang diterima oleh karyawan mencerminkan sikap karyawan dalam menjalani pekerjannya, sehingga bila karyawan sudah merasakan kepuasan dalam bekerja akan membuat karyawan semakin ingin meningkatkan kualitasnya pekerjaannya. Perasaan puas dalam bekerja belum dapat sepenuhnya dirasakan oleh karyawan CV. Wiracana, hal ini dibuktikan oleh hasil wawancara awal dengan 20 karyawan CV. Wiracana yang dipilih secara acak dari bagian marketing, accounting, purchasing, desain grafis, pengawas I-VI, housekeeping, bagian produksi didapatkan hasil bahwa 14 dari 20 karyawan CV Wiracana menyatakan bahwa mereka kurang puas dalam bekerja, yang menyebabkan rendahnya kepuasan kerja karyawan CV. Wiracana. Menurut Ardana dkk. (2012:148) seorang karyawan yang puas belum tentu terdorong untuk berprestasi karena kepuasannya tidak terletak pada motivasinya, akan tetapi dapat terletak pada faktor-faktor lain, misalnya pada imbalan yang diperolehnya.

Ketidakpuasan yang disebabkan karena masalah pembayaran atau masalah lingkungan kerja dan sebagainya, akan mengakibatkan karyawan bereaksi dengan berbagai cara, antara lain, bisa dengan menurunkan kinerjanya, mogok, atau menyampaikan keluhannya secara terbuka. Komitmen untuk loyal terhadap perusahaan dan kepuasan terhadap pekerjaan yang dirasakan oleh setiap karyawan akan terjalin bila organisasi memiliki iklim yang menunjang karyawan dalam bekerja dan adanya reward yang adil (Widodo, 2015).

Kompensasi atau reward diyakini sebagai salah satu faktor penentu untuk memotivasi karyawan untuk meningkatkan produktivitas sehingga dapat menghasilkan kinerja yang baik (Yudhaningsih, Ketut Sintaasih, \& Gede Riana, 2016). Lina (2014) menyatakan reward yaitu seluruh bentuk return untuk finansial ataupun non-finansial yang didapatkan pegawai dikarenakan jasa yang disumbangkan ke organisasi. Reward bisa berbentuk finansial merupakan gaji, upah, bonus, komisi, asuransi pegawai, bantuan social pegawai, tunjangan, libur ataupun cuti tapi terbayar, serta sebagainya. Reward non-finansial seperti peluang kenaikan pangkat, pengakuan dan lainnya.

Lingkungan kerja dapat mempengaruhi sumber daya manusia agar dapat bekerja dengan merasa nyaman, optimal dalam bekerja serta merasa puas bisa mengerjakan tugas dengan lingkungan yang kondusif. Susanty (2012) menyebutkan setiap organisasi memiliki iklim berbeda-beda yang bisa memberikan pengaruh prilaku Sumber Daya Manusia yang ada dalam perusahaan. Iklim organisasi dapat dilihat dari bagaimana karyawan dibina, dihargai dan diarahkan oleh perusahaan. Semakin tinggi iklim organisasi dalam sebuah organisasi maka semakin tingi pula komitmen organisasi.

Berdasarkan latar belakang tersebut peneliti tertarik untuk meneliti pengaruh iklim organisasi, sistem reward, kepuasan kerja dan komitmen organisasional di CV. Wiracana. Lokasi ini dipilih karena terdapat indikasi rendahnya kepuasan kerja dan komitmen organisasional yang bisa dilihat dari tingginya tingkat turnover karyawan $\mathrm{CV}$. Wiracana. 
Karyawan PT. Tiga Serangkai di Solo membuktikan bahwa iklim organisasi berpengaruh positif terhadap Kepuasan Kerja dalam penelitian Adiapsari (2012). Kurniasari dan Halim (2013) dalam penelitiannya pada Dinas pasar unit pasar Tanjung di kabupaten Jember menyebut bahwasannya, iklim perusahaan memiliki pengaruh yang signifikan serta memberi petunjuk pengaruh yang positif terhadap kepuasan kerja. Sari (2009) menyebutkan iklim organisasi berpengaruh positif terhadap kepuasan kerja. Penelitian ini dilakukan di British International School. Rahmawati (2015) memberi pernyataan bahwasannya iklim organisasi berpengaruh positif dan signifikan terhadap kepuasan kerja. Yuliana (2016) menyatakan bahwa iklim organisasi berpengaruh positif dan signifikan terhadap kepuasan kerja. Hal ini berarti semakin baik penerapan iklim organisasi, maka kepuasan kerja semakin meningkat. Berdasar kepada landasan teori serta penelitian sebelumnya bisa dikemukakan hipotesa sebagai berikut :

$\mathrm{H}_{1}$ : Iklim organisasi berpengaruh positif dan signifikan terhadap Kepuasan Kerja.

Beberapa penelitian telah dilakukan oleh para ahli reward merupakan faktor yang sangat penting yang berpengaruh terhadap kepuasan kerja karyawan. Khan (2014) menyatakan bahwa sistem reward berpengaruh positif terhadap kepuasan kerja. Penelitian ini dilakukan pada bank swasta di Pakistan. Sadhana dan Sintaasih (2015) menyatakan bahwa kompensasi finansial berpengaruh positif terhadap kepuasan kerja di Aura Commodation Ubud. Syah (2013) melakukan penelitian pada PT. Graha Raja Empat bahwa kompensasi finansial teruji berpengaruh positif terhadap kepuasan kerja dan motivasi kerja karyawan. Berdasarkan landasan teori dan penelitian sebelumnya dapat dikemukakan hipotesis sebagai berikut :

$\mathrm{H}_{2}$ : Sistem Reward berpengaruh positif dan signifikan terhadap Kepuasan Kerja.

Noordin et al. (2010) menyatakan bahwa iklim organisasi mempunyai pengaruh positif terhadap komitmen organisasi. Kurniasari dan Halim (2013) membuktikan bahwa iklim organisasi memiliki pengaruh yang positif terhadap komitmen perusahaan. Makin tingginya iklim organisasi didalam sebuah organisasi jadi makin tingi pula komitmen organisasi. Widiarti (2016) memberikan pernyataan iklim organisasi memiliki pengaruh positif pada komitmen organisasional. Adiapsari (2012) dalam penelitiannya pada karyawan PT. Tiga Serangkai di Solo membuktikan bahwa iklim organisasi berpengaruh positif terhadap komitmen organisasi. (Asriani, Nita, \& Supartha, 2017) dalam penelitiannya menyatakan bahwa iklim organisasi berpengaruh positif terhadap kepuasan kerja pada Grand Sinar Indah Hotel. Berdasar kepada landasan teori serta penelitian sebelum bisa dibentuk hipotesa sebagai berikut :

$\mathrm{H}_{3}$ : Iklim organisasi berpengaruh positif dan signifikan terhadap komitmen organisasional.

Beberapa penelitian telah dilakukan oleh para ahli sistem reward berpengaruh terhadap komitmen organisasi. Yudhaningsih dkk. (2016) dalam penelitiannya pada BPR di Kabupaten Gianyar menyebutkan bahwa sistem reward memiliki pengaruh terhadap komitmen organisasi. Gerald (2011) menyatakan bahwa reward berpengaruh terhadap komitmen organisasional untuk memotivasi dan bekerja lebih keras lagi untuk kinerja yang lebih baik. Berdasar kepada landasan teori serta penelitian sebelum bisa dibentuk hipotesa sebagai berikut : 
I Kadek Mahendra, dan Made Subudi. Pengaruh Iklim Organisasi dan Sistem Reward....

$\mathrm{H}_{4}$ : Sistem Reward berpengaruh positif dan signifikan terhadap Komitmen Organisasional.

Bhaesajsanguan (2010) membuktikan bahwa kepuasan kerja berpengaruh positif terhadap komitmen organisasi. Adiapsari (2010) menyatakan bahwa kepuasan kerja berpengaruh positif terhadap komitmen organisasi. Azem (2010) menyatakan bahwa kepuasan kerja berpengaruh positif terhadap komitmen organisasi. Khan (2014) dalam penelitiannya pada bank swasta di Pakistan menyatakan bahwa kepuasan kerja berpengaruh positif terhadap komitmen organisasi. Puspitawati dan Riana (2014) dalam penelitian di Hotel Bali Hyatt Sanur membuktikan bahwa kepuasan berpengaruh positif dan signifikan terhadap komitmen. Naderi (2012) dalam penelitiannya menyatakan ditemukan hubungan positif dan signifikan antara kepuasan kerja dengan komitmen organisasi. Berdasar kepada landasan teori serta penelitian sebelum bisa dibentuk hipotesa sebagai berikut :

$\mathrm{H}_{5}$ : Kepuasan Kerja berpengaruh positif dan signifikan terhadap Komitmen Organisasional

\section{METODE PENELITIAN}

Lokasi penelitian dilakukan di J1. Raya Sesetan, G3. Merpati No. 3, Denpasar Selatan. Ruang lingkup dalam penelitian ini antara lain, iklim organisasi dan sistem reward terhadap kepuasan kerja dan komitmen organisasional. Alasan yang melatarbelakangi peneliti melakukan penelitian di CV.Wiracana adalah ditemukannya masalah mengenai kepuasan kerja karyawan dan komitmen organisasional.

Tabel 2.

\section{Klasifikasi Variabel Penelitian}

\begin{tabular}{|c|c|c|}
\hline Variabel & Indikator & Sumber \\
\hline Iklim Organisasi & $\begin{array}{l}\text { Struktur organisasi } \\
\text { Tanggung jawab } \\
\text { Penghargaan } \\
\text { Dukungan } \\
\text { Komitmen }\end{array}$ & Rahmawati (2015) \\
\hline Sistem Reward & $\begin{array}{l}\text { Gaji } \\
\text { Insentif } \\
\text { Tunjangan }\end{array}$ & Yudhaningsih dkk.(2016) \\
\hline Kepuasan Kerja & $\begin{array}{l}\text { Pembayaran (Pay) } \\
\text { Pekerjaan (Job) } \\
\text { Kesempatan promosi (Promotion } \\
\text { opportunities) } \\
\text { Atasan (Supervisor) } \\
\text { Rekan kerja (Co-workers) }\end{array}$ & Azeem (2008) \\
\hline Komitmen Organisasional & $\begin{array}{l}\text { Komitmen Afektif } \\
\text { Komitmen Kontinyu } \\
\text { Komitmen Normatif }\end{array}$ & Meyer dan Allen (1991) \\
\hline $\begin{array}{l}\text { umber: Data Diolah, } 2018 \\
\text { Pengukuran data } \\
\text { Iwaban kuesioner yan } \\
\text { stem reward terhadap } \\
\text { Jiracana. Variabel beb }\end{array}$ & $\begin{array}{l}\text { lam penelitian ini mengg } \\
\text { terdiri atas pernyataan me } \\
\text { kepuasan kerja dan komi } \\
\text { dalam penelitian ini adal }\end{array}$ & $\begin{array}{l}\text { skala Likert. Berup } \\
\text { iklim organisasi da } \\
\text { organisasional di } \mathrm{Cl} \\
\mathrm{m} \text { organisasi }\left(\mathrm{X}_{1}\right) \mathrm{da}\end{array}$ \\
\hline
\end{tabular}


sistem reward $\left(\mathrm{X}_{2}\right)$. Variabel terikat dalam penelitian ini adalah kepuasan kerja $\left(\mathrm{Y}_{1}\right)$ dan komitmen organisasional $\left(\mathrm{Y}_{2}\right)$. Variabel pemediasi dalam penelitian ini adalah kepuasan kerja $\left(\mathrm{Y}_{1}\right)$. Variabel penelitian diukur menggunakan indikator tertentu yang diadopsi dari studi terdahulu, seperti disajikan pada Tabel 2.

Populasi dalam penelitian ini adalah seluruh karyawan $\mathrm{CV}$. Wiracana yang berjumlah 86 orang yang terdiri dari bagian marketing, accounting, purchasing, desain grafis, pengawas I-VI, housekeeping, bagian produksi. Metode yang digunakan dalam penentuan sampel adalah Sampling Jenuh yang berarti seluruh karyawan (populasi) dijadikan sampel.

Data dianalisis dengan statistik deskriptif, uji asumsi klasik, dan analisis jalur. Analisis deskriptif memiliki fungsi agar memberikan deskripsi ataupun memberikan gambaran pada obyek yang dilakukan penelitian melalui data sample ataupun populasi sebagaimana ada tidaknya, tidak melaksanakan analisa serta membentuk kesimpulan yang berlaku untuk umum (Sugiyono, 2014). Uji asumsi klasik dilaksanakan dengan tujuan agar memastikan hasil yang didapatkan pemenuhan asumsi dasar didalam analisa regresi. Hasil uji asumsi klasik yang dilaksanakan didalam penelitian beriku yaitu uji normalitas, uji multikoliniearitas serta uji heteroskedastisitas. Analisis jalur dikembangkan sebagai metode untuk mempelajari pengaruh, baik secara langsung maupun tidak langsung variabel independen iklim organisasi serta sistem reward pada variable dependen kepuasan kerja dan komitmen organisasional

\section{HASIL DAN PEMBAHASAN}

Pada tabel-tabel berikut disajikan hasil pengujian instrumen penelitian, profil responden, dan deskripsi variabel penelitian.

Tabel 3.

Profil Responden

\begin{tabular}{|c|c|c|c|c|}
\hline No & Variabel & Klasifikasi & Jumlah & Persentase $(\%)$ \\
\hline \multirow{2}{*}{1} & \multirow{2}{*}{ Jenis Kelamin } & Perempuan & 49 & 56,98 \\
\hline & & Laki-laki & 37 & 43,02 \\
\hline & & Jumlah & 86 & 100 \\
\hline \multirow{4}{*}{2} & \multirow{4}{*}{ Usia } & 21-30 Tahun & 33 & 38,37 \\
\hline & & 31-40 Tahun & 28 & 32,56 \\
\hline & & 41 - 50 Tahun & 19 & 22,09 \\
\hline & & $\geq 51$ Tahun & 6 & 6,98 \\
\hline & & Jumlah & 86 & 100 \\
\hline \multirow{8}{*}{3} & \multirow{8}{*}{ Jabatan } & Marketing & 9 & 10,47 \\
\hline & & Accounting & 2 & 2,33 \\
\hline & & Purchasing & 4 & 4,65 \\
\hline & & Design Grafis & 3 & 3,49 \\
\hline & & Pengawas I s.d VI & 6 & 6,98 \\
\hline & & House Keeping & 5 & 5,81 \\
\hline & & Bagian Produksi & 57 & 66,28 \\
\hline & & Jumlah & $\underline{86}$ & 100 \\
\hline
\end{tabular}

Sumber: Data Diolah, 2018

Tabel 3. memberi petunjuk bahwa responden memiliki jenis kelamin perempuan berjumlah 49 orang $(56,98 \%)$ lebih banyak dibandingkan dengan responden laki-laki yang berjumlah $37(43,02 \%)$. Hasil klasifikasi berdasarkan usia 
I Kadek Mahendra, dan Made Subudi. Pengaruh Iklim Organisasi dan Sistem Reward....

menunjukkan bahwa responden dengan rentang usia 21-30 tahun $(38,37 \%)$ paling mendominasi dibandingkan dengan rentang usia 31-40 tahun, 41-50 tahun dan $\geq 50$ tahun. Hasil klasifikasi berdasarkan jabatan, didominasi oleh responden dengan jabatan bagian produksi yaitu sebesar 57 orang $(66,28 \%)$ dibandingkan dengan responden dengan jabatan lainnya.

Tabel 4.

Rekapitulasi Hasil Uji Validitas Instrumen Penelitian

\begin{tabular}{ccccc}
\hline Variabel & Indikator & $\begin{array}{c}\text { Koefisien } \\
\text { Korelasi }\end{array}$ & $\begin{array}{c}\text { Sig. (2- } \\
\text { tailed })\end{array}$ & Keterangan \\
\hline \multirow{3}{*}{ Iklim organisasi $\left(\mathrm{X}_{1}\right)$} & $\mathrm{X}_{1.1}$ & 0,831 & 0,000 & Valid \\
& $\mathrm{X}_{1.2}$ & 0,873 & 0,000 & Valid \\
& $\mathrm{X}_{1.3}$ & 0,889 & 0,000 & Valid \\
& $\mathrm{X}_{1.4}$ & 0,906 & 0,000 & Valid \\
& $\mathrm{X}_{1.5}$ & 0,911 & 0,000 & Valid \\
\hline \multirow{3}{*}{ Sistem reward $\left(\mathrm{X}_{2}\right)$} & $\mathrm{X}_{2.1}$ & 0,923 & 0,000 & Valid \\
& $\mathrm{X}_{2.2}$ & 0,929 & 0,000 & Valid \\
& $\mathrm{X}_{2.3}$ & 0,894 & 0,000 & Valid \\
\hline \multirow{3}{*}{ Kepuasan kerja $\left(\mathrm{Y}_{1}\right)$} & $\mathrm{Y}_{1.1}$ & 0,916 & 0,000 & Valid \\
& $\mathrm{Y}_{1.2}$ & 0,884 & 0,000 & Valid \\
& $\mathrm{Y}_{1.3}$ & 0,899 & 0,000 & Valid \\
& $\mathrm{Y}_{1.4}$ & 0,913 & 0,000 & Valid \\
& $\mathrm{Y}_{1.5}$ & 0,922 & 0,000 & Valid \\
\hline \multirow{2}{*}{ Komitmen } & $\mathrm{Y}_{2.1}$ & 0,913 & 0,000 & Valid \\
& $\mathrm{Y}_{2.2}$ & 0,914 & 0,000 & Valid \\
& $\mathrm{Y}_{2.3}$ & 0,924 & 0,000 & Valid \\
\hline
\end{tabular}

Sumber: Data Diolah, 2018

Tabel 4. memberi petunjuk bahwasannya semua instrumen penelitian yang dipakai agar memberi pengukuran variable iklim organisasi, sistem reward, kepuasan kerja serta komitmen organisasional mempunyai nilai koefisien korelasi dengan skor total semua butir pernyataan lebih tinggi daripada 0,30 dengan signifikansi dibawah 0,05 . Hal ini memberi petunjuk bahwasannya item-item pernyataan didalam instrumen penelitian itu valid serta layak dipakai sebagai instrumen penelitian.

Tabel 5.

Rekapitulasi Hasil Uji Reliabilitas Instrumen Penelitian

\begin{tabular}{clcc}
\hline No. & \multicolumn{1}{c}{ Variabel } & Cronbach's Alpha & Keterangan \\
\hline $\mathbf{1}$ & Iklim organisasi $\left(\mathrm{X}_{1}\right)$ & 0,823 & Reliabel \\
$\mathbf{2}$ & Sistem reward $\left(\mathrm{X}_{2}\right)$ & 0,867 & Reliabel \\
$\mathbf{3}$ & Kepuasan kerja $\left(\mathrm{Y}_{1}\right)$ & 0,827 & Reliabel \\
$\mathbf{4}$ & Komitmen & 0,868 & Reliabel \\
& organisasional $\left(\mathrm{Y}_{2}\right)$ & & \\
\hline
\end{tabular}

Sumber: Data Diolah, 2018

Hasil penguujian reliabilitas yang tersaji didalam Tabel 5 memberi petunjuk bahwasannya semua instrument penelitian mempunyai koefisien Cronbach's Alpha melebihi 0,60. Jadi bisa dinyatakan bahwasannya semua variable sudah memberikan kepenuhan syarat reliabilitas ataupun kehandalan hingga bisa berguna agar melaksanakan penelitian. 
Tabel 6.

Hasil Uji Normalitas Struktur 1

\begin{tabular}{cc}
\hline & Unstandardized Residual \\
\hline $\mathrm{N}$ & 86 \\
Kolmogorov-Smirnov $Z$ & 0,696 \\
Asymp.Sig.(2-tailed) & 0,718 \\
\hline Sumber: Data Diolah, 2018
\end{tabular}

Berdasar kepada Tabel.6 bisa terlihat bahwasannya nilai Kolmogorov Sminarnov (K-S) sejumlah 0,696, namun nilai Asymp. Sig. (2-tailed) sejumlah 0,718 . Hasil itu memberikan indikasi bahwasannya model persamaan regresi itu mempunyai distribusi normal dikarenakan nilai Asymp. Sig. (2-tailed) 0,718 lebih besar daripada nilai alpha 0,05 .

Tabel 7.

Hasil Uji Normalitas Struktur 2

\begin{tabular}{cc}
\hline & Unstandardized Residual \\
\hline $\mathrm{N}$ & 86 \\
Kolmogorov-Smirnov $Z$ & 0,984 \\
Asymp.Sig.(2-tailed) & 0,288 \\
\hline Sumber: Data Diolah, 2018 &
\end{tabular}

Berdasar kepada Tabel.7 bisa dilihat bahwasannya nilai Kolmogorov Sminarnov (K-S) sejumlah 0,984, sedang nilai Asymp. Sig. (2-tailed) sejumlah 0,288 . Hasil itu memberikan indikasi bahwasannya model persamaan regresi itu mempunyai distribusi normal dikarenakan nilai Asymp. Sig. (2-tailed) 0,288 melebihi besar daripada nilai alpha 0,05 .

Tabel 8.

Hasil Uji Multikoleniaritas Struktur 1

\begin{tabular}{ccc}
\hline Variabel & Tolerance & VIF \\
\hline Iklim organisasi (X1) & 0,567 & 1,764 \\
Sistem reward (X2) & 0,567 & 1,764 \\
\hline
\end{tabular}

Sumber: Data Diolah, 2018

Berdasar kepada Tabel 8, bisa terlihat bahwasannya nilai tolerance serta VIF daripada variable iklim organisasi, juga sistim reward. Nilai itu memberi petunjuk bahwasannya nilai tolerance agar tiap-tiap variable lebih besar dari $10 \%$ dan nilai VIF lebih kecil dari 10 yang memiliki arti model persamaan regresi 1 bebas daripada multikolinearitas.

Tabel 9.

Hasil Uji Multikoleniaritas Struktur 2

\begin{tabular}{ccc}
\hline Variabel & Tolerance & VIF \\
\hline Iklim organisasi (X1) & 0,392 & 2,552 \\
Sistem reward (X2) & 0,462 & 2,164 \\
Kepuasan kerja (Y1) & 0,342 & 2,927 \\
\hline
\end{tabular}

Sumber: Data Diolah, 2018

Berdasar kepada Tabel 9, bisa terlihat bahwasannya nilai tolerance juga VIF daripada variable Iklim organisasi, sistem reward, serta kepuasan kerja. Nilai itu memberi petunjuk bahwasannya nilai tolerance bagi tiap-tiap variable melebihi 
I Kadek Mahendra, dan Made Subudi. Pengaruh Iklim Organisasi dan Sistem Reward....

10\% juga nilai VIF lebih kecil daripada 10 yang mempunyai arti model persamaan regresi 2 terbebas dari multikolinearitas.

Tabel 10.

Hasil Uji Heteroskedastisitas Struktur 1

\begin{tabular}{|c|c|c|c|c|c|}
\hline \multirow[t]{2}{*}{ Model } & \multicolumn{2}{|c|}{$\begin{array}{c}\text { Unstandardized } \\
\text { Coefficients }\end{array}$} & \multirow{2}{*}{$\begin{array}{c}\begin{array}{c}\text { Standardized } \\
\text { Coefficients }\end{array} \\
\text { Beta }\end{array}$} & \multirow[b]{2}{*}{$\mathrm{t}$} & \multirow[b]{2}{*}{ Sig. } \\
\hline & $\mathrm{B}$ & Std. Error & & & \\
\hline (Constant) & 1.363 & .729 & & 1.869 & .065 \\
\hline Iklim organisasi & .073 & .056 & .185 & 1.298 & .198 \\
\hline Sistem reward & .018 & .090 & .028 & .198 & .844 \\
\hline
\end{tabular}

Sumber: Data Diolah, 2018

Pada Tabel 10,dapat dilihat bahwasannya nilai signifikansi daripada variable iklim organisasi sejumlah 0,198 serta sistem reward sejumlah 0,844 melebihi 0,05 yang berarti tak ada pengaruh diantara variable independen terhadap absolute residual. Dengan begitu, model yang dibuat tak mengandung gejala heteroskedastisitas.

Tabel 11.

Hasil Uji Heteroskedastisitas Struktur 2

\begin{tabular}{llrrrrr}
\hline \multirow{2}{*}{ Model } & \multicolumn{2}{c}{$\begin{array}{c}\text { Unstandardized } \\
\text { Coefficients }\end{array}$} & \multicolumn{2}{c}{$\begin{array}{c}\text { Standardized } \\
\text { Coefficients }\end{array}$} & & \\
\cline { 3 - 5 } & \multicolumn{1}{c}{ B } & Std. Error & Beta & \multicolumn{1}{c}{ t } & \multicolumn{1}{c}{ Sig. } \\
\hline 1 & (Constant) & 1.044 & .491 & & 2.124 & .037 \\
& Iklim organisasi & .056 & .046 & .208 & 1.221 & .226 \\
& Sistem reward & -.111 & .067 & -.258 & -1.644 & .104 \\
& Kepuasan kerja & .046 & .045 & .188 & 1.030 & .306 \\
\hline
\end{tabular}

Sumber: Data Diolah, 2018

Pada Tabel 11, bisa terlihat bahwasannya nilai signifikansi dari variable iklim organisasi, sistem reward juga kepuasan kerja masing-masing sejumlah 0,226; 0,104 , serta 0,306 . Nilai itu melebihi 0,05 yang mempunyai arti tak adanya pengaruh diantara variable bebas terhadap absolute residual. Dengan begitu, model yang dibuat tak mengandung gejala heteroskedastisitas.

Proses menghitung koefisien path dilaksanakan dengan analisis regresi lewat software SPSS 18.0 for Windows, didapatkan hasil yang ditunjukan di Tabel 12 , berikut.

Tabel 12.

Hasil Analisis Jalur Struktur 1

\begin{tabular}{|c|c|c|c|c|c|c|}
\hline \multirow{2}{*}{\multicolumn{2}{|c|}{ Model }} & \multicolumn{2}{|c|}{$\begin{array}{c}\text { Unstandardized } \\
\text { Coefficients }\end{array}$} & \multirow{2}{*}{$\begin{array}{c}\text { Standardized } \\
\text { Coefficients } \\
\text { Beta } \\
\end{array}$} & \multirow[b]{2}{*}{$\mathrm{t}$} & \multirow[b]{2}{*}{ Sig. } \\
\hline & & $\mathrm{B}$ & Std. Error & & & \\
\hline \multirow[t]{7}{*}{1} & (Constant) & -.073 & 1.199 & & -.061 & .952 \\
\hline & Iklim organisasi & .565 & .093 & .519 & 6.089 & .000 \\
\hline & Sistem reward & .643 & .148 & .370 & 4.338 & .000 \\
\hline & F Hitung & & & & & 79,958 \\
\hline & Signifikansi & & & & & 0,000 \\
\hline & $\mathrm{R}_{1}$ Square & & & & & 0,658 \\
\hline & Adjusted $\mathrm{R}_{1}$ Square & & & & & 0,650 \\
\hline
\end{tabular}

Sumber: Data Diolah, 2018

Berdasar kepada hasil analisis jalur substruktur 1 seperti yang tersaji di Tabel 12, jadi persamaan strukturalnya yaitu seperti berikut : 


$$
\begin{aligned}
& Y_{1}=\beta_{1} X_{1}+\beta_{2} X_{2}+e_{1} \ldots \ldots \ldots \ldots \\
& \mathrm{Y} 1=0,565 \mathrm{X} 1+0,643 \mathrm{X} 2+\mathrm{e}_{1}
\end{aligned}
$$

Nilai koefisien regresi variabel iklim organisasi dan sistem reward, mempunyai nilai positif dengan nilai signifikansi uji t kurang daripada 0,05. Nilai itu memberi petunjuk bahwasannya variable iklim organisasi serta sistem reward, mempunyai pengaruh positif dan signifikan terhadap variabel kepuasan kerja. Besar atau tidaknya pengaruh variabel independen terhadap variable dependen yang ditampilkan oleh nilai determinasi total ( $\mathrm{R}_{1}$ Square) sejumlah 0,658 memiliki arti bahwasannya sejumlah 65,8\% variasi kepuasan kerja dipengaruhi oleh variasi iklim organisasi serta sistem reward, sedangkan sisanya sebesar $34,2 \%$ dijelaskan oleh faktor lain yang tidak dimasukkan ke dalam model.

Tabel 13.

\begin{tabular}{|c|c|c|c|c|c|c|}
\hline \multirow{2}{*}{\multicolumn{2}{|c|}{ Model }} & \multicolumn{2}{|c|}{$\begin{array}{c}\text { Unstandardized } \\
\text { Coefficients }\end{array}$} & \multirow{2}{*}{$\begin{array}{c}\begin{array}{l}\text { Standardized } \\
\text { Coefficients }\end{array} \\
\text { Beta }\end{array}$} & \multirow[b]{2}{*}{$\mathrm{t}$} & \multirow[b]{2}{*}{ Sig. } \\
\hline & & $\mathrm{B}$ & Std. Error & & & \\
\hline \multirow[t]{8}{*}{1} & (Constant) & 1.814 & .756 & & 2.401 & .019 \\
\hline & Iklim Organisasi & 197 & .070 & 327 & 2.794 & .006 \\
\hline & Sistem Reward & 219 & .104 & 228 & 2.113 & .038 \\
\hline & Kepuasan Kerja & .153 & .069 & 277 & 2.209 & .030 \\
\hline & F Hitung & & & & & 34,842 \\
\hline & Signifikansi & & & & & 0,000 \\
\hline & $\mathrm{R}_{2}$ Square & & & & & 0,560 \\
\hline & Adjusted $\mathrm{R}_{2}$ Square & & & & & 0,544 \\
\hline
\end{tabular}

Hasil Analisis Jalur Struktur 2

Berdasar kepada hasil analisis jalur substruktur 2 seperti yang tersaji di Tabel 13, maka persamaan strukturalnya yaitu seperti berikut:

$$
\begin{aligned}
& Y_{2}=\beta_{3} X_{1}+\beta_{4} X_{2}+\beta_{5} Y_{1}+e_{2} \ldots \ldots \ldots \ldots \ldots \ldots \ldots \ldots \ldots \ldots \ldots \\
& \mathrm{Y} 2=0,197 \mathrm{X} 1+0,219 \mathrm{X} 2+0,153 \mathrm{Y} 1+\mathrm{e}_{2}
\end{aligned}
$$

Nilai koefisien regresi masing-masing variabel iklim organisasi, sistem reward dan kepuasan kerja bernilai positif dengan nilai signifikansi uji t kurang dari 0,050 . Hal ini menunjukkan bahwa variabel iklim organisasi, sistem reward dan kepuasan kerja mempunyai pengaruh positif serta signifikan pada variabel dependen. Besar atau tidaknya pengaruh variable independen pada variable dependen yang ditampilkan oleh nilai determinasi total $\left(\mathrm{R}_{2}\right.$ Square) sejumlah 0,560 memiliki arti bahwasannya sejumlah 56\% variasi komitmen organisasional dipengaruhi oleh variasi iklim organisasi, sistem reward dan kepuasan kerja, sedangkan sisanya sebesar $44 \%$ dijelaskan oleh faktor lain yang tidak dimasukkan ke dalam model.

Besarnya Pengaruh langsung (Direct effect / DE) pada variabel iklim organisasi terhadap kepuasan kerja berdasarkan table 13 , adalah sebesar 0,565 ( $\mathrm{X}_{1}$ $\left.\rightarrow \mathrm{Y}_{1}=\mathrm{p} 1=0,565\right)$. Besarnya pengaruh langsung variabel Sistem reward terhadap Kepuasan kerja sebesar $0,643\left(\mathrm{X}_{2} \rightarrow \mathrm{Y}_{1}=\mathrm{p} 2=0,643\right)$. Pengaruh langsung variabel Iklim organisasi terhadap Komitmen organisasional Berdasarkan table 14 sebesar $0,197\left(\mathrm{X}_{1} \rightarrow \mathrm{Y}_{2}=\mathrm{p} 3=0,197\right)$. Berdasarkan tabel 14 besarnya pengaruh langsung variabel Sistem reward terhadap Komitmen organisasional sebesar 0,219 $\left(\mathrm{X}_{2} \rightarrow \mathrm{Y}_{2}\right.$ 
I Kadek Mahendra, dan Made Subudi. Pengaruh Iklim Organisasi dan Sistem Reward....

$=\mathrm{p} 4=0,219)$. besarnya pengaruh langsung variabel Kepuasan kerja terhadap Komitmen organisasional berdasarkan table 14, adalah sebesar 0,153 $\left(\mathrm{Y}_{1} \rightarrow \mathrm{Y}_{2}=\right.$ p5 $=0,153)$.

Pengaruh tidak langsung (Indirect effect, / IE) variabel Iklim organisasi terhadap Komitmen organisasional melalui Kepuasan kerja adalah $\mathrm{X}_{1} \rightarrow \mathrm{Y}_{1} \rightarrow \mathrm{Y}_{2}$ $=(\mathrm{p} 1 \times \mathrm{p} 5)=(0,565 \times 0,153)=0,086$. Nilai sebesar 0,086 memiliki arti bahwa pengaruh tidak langsung variabel Iklim organisasi terhadap Komitmen organisasional melalui Kepuasan kerja sebesar 8,6\%. Hal ini berarti iklim organisasi berpengaruh tidak langsung terhadap komitmen organisasional melalui kepuasan kerja pada karyawan CV. Wiracana. Pengaruh variabel Sistem reward terhadap Komitmen organisasional melalui Kepuasan kerja adalah $\mathrm{X}_{2} \rightarrow \mathrm{Y}_{1} \rightarrow \mathrm{Y}_{2}$ $=(\mathrm{p} 2 \times \mathrm{p} 5)=(0,643 \times 0,153)=0,098$. Nilai sebesar 0,098 memiliki arti bahwa pengaruh tidak langsung variabel Sistem reward terhadap Komitmen organisasional melalui Kepuasan kerja sebesar 9,8\%. Hal ini berarti sistem reward berpengaruh tidak langsung terhadap komitmen organisasional melalui kepuasan kerja pada karyawan CV. Wiracana.

Tabel 14.

Pengaruh Langsung dan Pengaruh Tidak Langsung variabel iklim organisasi $\left(\mathrm{X}_{1}\right)$, sistem reward $\left(\mathrm{X}_{2}\right)$, kepuasan kerja $\left(\mathrm{Y}_{1}\right)$, dan komitmen organisasional $\left(\mathbf{Y}_{2}\right)$

\begin{tabular}{|c|c|c|}
\hline Pengaruh Variabel & Langsung & $\begin{array}{c}\text { Tidak Langsung Melalui } \\
\text { Y1 }\end{array}$ \\
\hline $\begin{array}{c}\mathrm{X}_{1} \rightarrow \mathrm{Y}_{1} \\
\text { (Pengaruh iklim organisasi terhadap kepuasan kerja) }\end{array}$ & 0,565 & - \\
\hline $\begin{array}{c}\mathrm{X}_{2} \rightarrow \mathrm{Y}_{1} \\
\text { (Pengaruh sistem reward terhadap kepuasan kerja) }\end{array}$ & 0,643 & - \\
\hline $\begin{array}{c}\mathrm{X}_{1} \rightarrow \mathrm{Y}_{2} \\
\text { (Pengaruh iklim organisasi terhadap komitmen } \\
\text { organisasional) }\end{array}$ & 0,197 & $\begin{array}{c}X_{1} \rightarrow \mathrm{Y}_{1} \rightarrow \mathrm{Y}_{2} \\
\quad(\mathrm{p} 1 \times \mathrm{p} 5) \\
(0,565 \times 0,153)=0,086\end{array}$ \\
\hline $\begin{array}{c}\mathrm{X}_{2} \rightarrow \mathrm{Y}_{2} \\
\text { (Pengaruh sistem reward terhadap komitmen } \\
\text { organisasional) }\end{array}$ & 0,219 & $\begin{array}{c}\mathrm{X}_{2} \underset{(\mathrm{Y} 2 \times \mathrm{Y} 5)}{\rightarrow} \mathrm{Y}_{2} \\
(0,643 \times 0,153)=0,098\end{array}$ \\
\hline $\begin{array}{c}\mathrm{Y}_{1} \rightarrow \mathrm{Y}_{2} \\
\text { (Pengaruh kepuasan kerja terhadap komitmen } \\
\text { organisasional) }\end{array}$ & 0,153 & - \\
\hline
\end{tabular}

Sumber: Data Diolah, 2018

Berdasar kepada model substruktur 1 juga substruktur 2, jadi bisa disusun model diagram jalur akhir. Sebelum membuat susunan model diagram jalur akhir, lebih dulu hitung nilai standar eror seperti berikut:

$$
\begin{aligned}
& \mathrm{Pe}_{\mathrm{i}}=\sqrt{1-\mathrm{R}_{\mathrm{i}}^{2}} \\
& \text { Substruktur 1: } \\
& \mathrm{Y} 1=0,565 \mathrm{X} 1+0,643 \mathrm{X} 2+\mathrm{e}_{1} \\
& \mathrm{Pe}_{1}=\sqrt{1-0,658}=\sqrt{0,342}=0,585 \\
& \text { Substruktur 2: } \\
& \mathrm{Y} 2=0,197 \mathrm{X} 1+0,219 \mathrm{X} 2+0,153 \mathrm{Y} 1+\mathrm{e}_{2} \\
& \mathrm{Pe}_{2}=\sqrt{1-0,560}=\sqrt{0,440}=0,663
\end{aligned}
$$


Berdasar kepada proses menghitung pengaruh error (Pei), diperoleh hasil pengaruh error $\left(\mathrm{Pe}_{1}\right)$ sejumlah 0,585 serta pengaruh error $\left(\mathrm{Pe}_{2}\right)$ sejumlah 0,663. Hasil koefisien determinasi total adalah sebagai berikut:

$$
\begin{aligned}
\mathrm{R}^{2} \mathrm{~m} & =1-\left(\mathrm{Pe}_{1}\right)^{2}\left(\mathrm{Pe}_{2}\right)^{2} \ldots \ldots \ldots \\
& =1-(0,585)^{2}(0,663)^{2} \\
& =1-(0,342)(0,439) \\
& =1-0,150=0,850
\end{aligned}
$$

Nilai determinasi total sejumlah 0,850 memiliki arti bahwasannya senilai $85 \%$ variasi komitmen organisasional dipengaruhi oleh variasi iklim organisasi, sistem reward dan kepuasan kerja dan sisanya senilai 15\% dapat ditunjukkan oleh factor-faktor lainnya yang tak termasuk kedalam model. Langkah akhir berikut akan memberikan penjelasan hasil daripada proses menghitung koefisien jalur yang ditampilkan lewat nilai Standardized Coefficient di masing-masing pengaruh hubungan diantara variable. Berikut ini tersaji nilai koefisien jalur masing-masing pengaruh variable lewat Gambar 1.

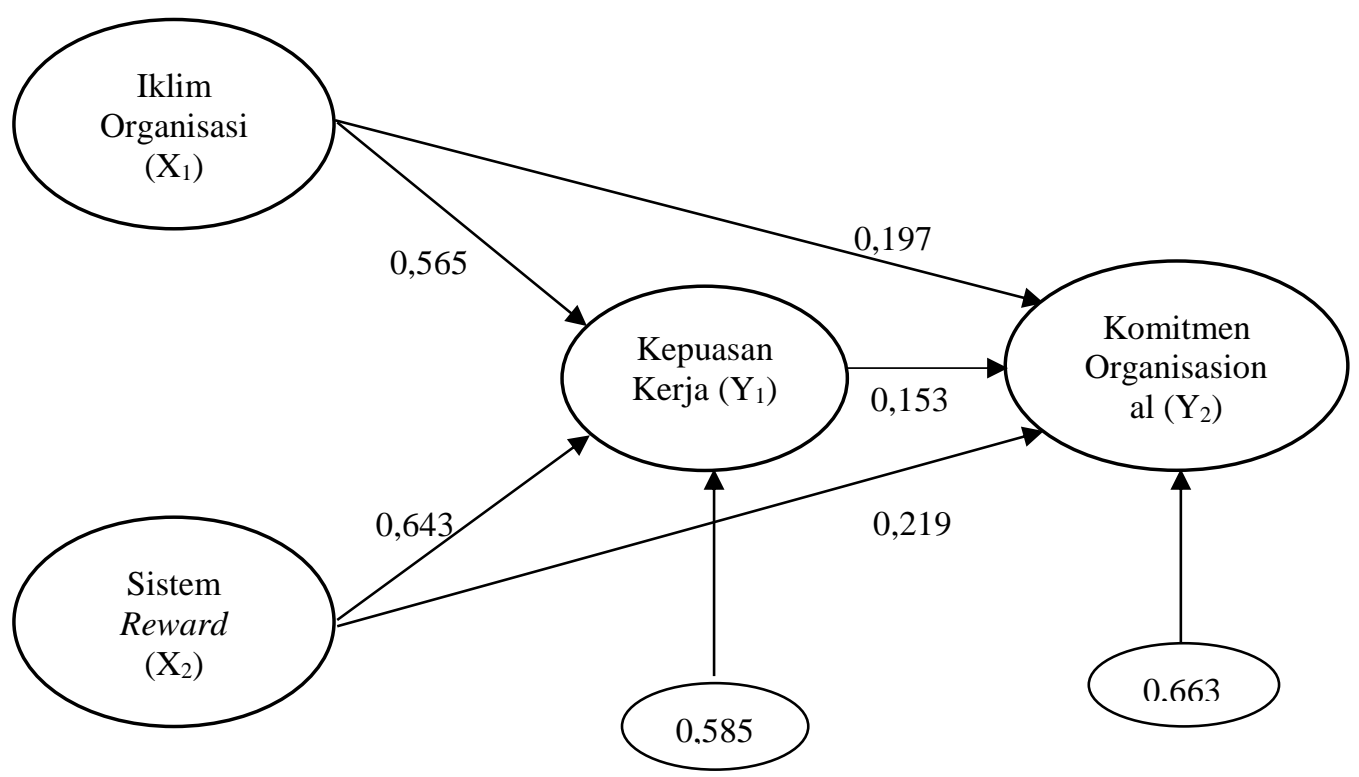

\section{Gambar 1. Model Diagram Jalur Akhir}

Sumber: Data Diolah, 2018

Berdasarkan hasil analisis pengaruh iklim organisasi terhadap kepuasan kerja karyawan didapatkan nilai Signifikansi t sejumlah 0,000 dengan nilai koefisien beta 0,565. Nilai Signifikansi t $0,000<0,05$ memberikan indikasi bahwasannya $\mathrm{H}_{0}$ ditolak serta $\mathrm{H}_{1}$ diterima. Hasil berikut memiliki arti bahwasannya iklim organisasi memiliki pengaruh positif juga signifikan terhadap kepuasan kerja karyawan CV. Wiracana. Pengaruh sistem reward terhadap kepuasan kerja didapatkan nilai signifikansi t sejumlah 0,000 dengan nilai koefisien beta 0,643 . Nilai signifikansi t $0,004<0,05$ memberikan indikasi bahwasannya $\mathrm{H}_{0}$ ditolak serta $\mathrm{H}_{2}$ diterima. Hasil tersebut memiliki arti bahwasannya sistem reward memiliki pengaruh positif juga signifikan terhadap kepuasan kerja karyawan CV. Wiracana. Pengaruh iklim organisasi terhadap komitmen organisasional didapatkan nilai signifikansi $t$ sejumlah 0,006 dengan nilai koefisien beta 0,197. Nilai signifikansi t 0,006 0,05 
memberikan indikasi bahwasannya $\mathrm{H}_{0}$ ditolak serta $\mathrm{H}_{3}$ diterima. Hasil tersebut memiliki arti bahwasannya iklim organisasi mempunyai pengaruh positif serta signifikan terhadap komitmen organisasional.

Berdasar kepada hasil analisis pengaruh sistem reward terhadap komitmen organisasional didapatkan nilai signifikansi t sejumlah 0,038 dengan nilai koefisien beta 0,219 . Nilai signifikansi t $0,038<0,05$ memberikan indikasi bahwasannya $\mathrm{H}_{0}$ ditolak serta $\mathrm{H}_{4}$ diterima. Hasil berikut memiliki arti bahwasannya Sistem reward mempunyai pengaruh positif juga signifikan pada komitmen organisasional. Berdasar kepada hasil analisis pengaruh kepuasan kerja terhadap komitmen organisasional didapatkan nilai signifikansi t sejumlah 0,030 dengan nilai koefisien beta 0,153 . Nilai Sig. t $0,030<0,05$ memberikan indikasi bahwasannya $\mathrm{H}_{0}$ ditolak dan $\mathrm{H}_{5}$ diterima. Hasil tersebut memiliki arti bahwasannya kepuasan kerja karyawan memiliki pengaruh positif serta signifikan terhadap komitmen organisasional.

Berdasar kepada hasil penelitian yang didapatkan ada sekian implikasi strategis adalah sebagai berikut: satu, hasil survei memberikan petunjuk bahwasannya indikator dukungan jadi faktor penting didalam memberikan peningkatan iklim organisasi yang bagus. Dengan adanya sikap saling mendukung antar sesama karyawan CV. Wiracana maka iklim organisasi mampu terbentuk dengan baik, sehingga hal tersebut patut dipertahankan oleh CV. Wiracana. Kedua, hasil survei menunjukkan bahwa indikator yang menjadi faktor penting dalam meningkatkan penilaian karyawan pada sistem reward adalah indikator Gaji. Hal ini disebabkan karena karyawan menilai bahwa sistem gaji berdasarkan waktu kerja mereka pada $\mathrm{CV}$. Wiracana sudah cukup sesuai, sehingga hal tersebut dapat dipertahankan oleh perusahaan agar pandangan karyawan pada sistem reward CV. Wiracana semakin baik.

Ketiga, hasil survei menunjukkan bahwa tinggi rendahnya kepuasan kerja karyawan disebabkan oleh indikator rekan kerja. Hal tersebut disebabkan karena sudah terjalin interaksi yang baik sesama rekan kerja pada karyawan CV. Wiracana, sehingga karyawan tersebut puas bekerja pada CV. Wiracana. Kemudian implikasi terakhir yaitu mengenai komiemen organisasional karyawan, dimana hasil survei menunjukkan bahwa semakin tinggi komitmen karyawan disebabkan oleh indikator komitmen kontinyu. Hal ini disebabkan karena sebagian besar karyawan merasa akan menghadapi Resiko yang besar apabila meninggalkan organisasi, sehingga hal tersebut dapat di evaluasi kembali oleh CV. Wiracana agar komitmen karyawan semakin meningkat.

\section{SIMPULAN DAN SARAN}

Hasil analisis penelitian dan hasil pembahasan pada bab sebelumnya maka simpulan dari penelitian ini adalah sebagai berikut: 1) Iklim organisasi berpengaruh positif dan signfikan terhadap kepuasan kerja karyawan CV. Wiracana. Hal ini menunjukan bahwa semakin baik penerapan iklim organisasi pada CV. Wiracana, maka akan semakin meningkatkan kepuasan kerja karyawan pada CV. Wiracana. 2) Sistem reward berpengaruh positif dan signfikan terhadap kepuasan kerja karyawan CV. Wiracana. Hal ini berarti bahwa, dengan memperoleh sistem reward yang tinggi maka karyawan akan semakin puas bekerja di CV. Wiracana. 3) Iklim organisasi berpengaruh positif dan signfikan terhadap komitmen organisasional 
karyawan CV. Wiracana. Hal ini menunjukan bahwa semakin baik penerapan iklim organisasi pada CV. Wiracana, maka akan semakin meningkatkan komitmen karyawan pada CV. Wiracana. 4) Sistem reward berpengaruh positif dan signfikan terhadap komitmen organisasional karyawan CV. Wiracana. Hal ini berarti bahwa, dengan memperoleh sistem reward yang tinggi maka karyawan akan termotivasi untuk bekerja lebih baik sehingga komitmen karyawan pada CV. Wiracana akan semakin meningkat. 5) Kepuasan kerja berpengaruh positif dan signifikan terhadap Komitmen organisasional karyawan CV. Wiracana. Hal ini berarti bahwa, dengan memiliki kepuasan kerja yang tinggi maka karyawan akan lebih semangat untuk bekerja lebih baik sehingga komitmen karyawan pada CV. Wiracana akan semakin meningkat.

Saran yang dapat dipergunakan sebagai bahan pertimbangan dalam menentukan kebijakan terkait kepuasan kerja dan komitmen organisasional karyawan CV. Wiracana dimasa mendatang, antara lain: 1) Dalam upaya menjaga iklim organisasi yang kondusif, maka sebaiknya pihak manajemen CV. Wiracana meningkatkan sistem pembagian tugas agar sesuai dengan kemampuan individu karyawan, memberikan imbalan yang sesuai dengan hasil kerja keras karyawan dan menjaga komitmen agar karyawan memiliki rasa bangga untuk bekerja di CV. Wiracana. 2) Dalam upaya meningkatkan sistem reward tersebut, maka sebaiknya pihak manajemen CV. Wiracana melakukan evaluasi kembali terhadap sistem insentif yang diberikan pada karyawannya ketika bekerja melebihi waktu standar dan juga mengevaluasi tunjangan kesejahteraan yang diberikan, agar karyawan merasa loyal, puas dan berkomitmen tinggi terhadap CV. Wiracana. 3) Dalam upaya meningkatkan kepuasan kerja karyawan, maka sebaiknya pihak manajemen CV. Wiracana memperhatikan dukungan atasan terhadap karyawan, kesesuaian gaji karyawan dan kesempatan naik jabatan pada seluruh karyawan dan secara adil dengan menyesuaikan kemampuan dan keahlian karyawan tersebut. 4) Dalam upaya meningkatkan Komitmen organisasional karyawan CV. Wiracana, maka sebaiknya pihak manajemen CV. Wiracana memberikan pemahaman pada seluruh karyawan tentang pentingnya komitmen pada sebuah organisasi, selain itu pihak manajemen CV. Wiracana sebaiknya lebih meningkatkan hubungan keakraban antara sesama rekan kerja maupun atasan, agar karyawan merasa nyaman bekerja di CV. Wiracana dan komitmen organisasional karyawan akan meningkat. 5) Bagi penelitian selanjutnya disarankan untuk menambahkan faktor lain yang dapat mempengaruhi komitmen organisasional seperti faktor personal yang meliputi job expectations, psychological contract, job choice factor, karakteristik personal ataupun faktor lainnya.

\section{REFERENSI}

Asriani, N. W., Nita, I. W., \& Supartha, G. (2017). KOMITMEN

ORGANISASIONAL KARYAWAN DIPENGARUHI OLEH IKLIM

ORGANISASI DAN KEPUASAN KERJA PADA GRAND SINAR INDAH

HOTEL. 6(11), 5999-6028.

Azeem, S.M., 2010. JOB SATISFACTION AND ORGANIZATIONAL COMMITMENT AMONG EMPLOYEES IN THE SULTANATE OF OMAN. Psychology, 1(4), Pp: 295. 
I Kadek Mahendra, dan Made Subudi. Pengaruh Iklim Organisasi dan Sistem Reward....

Bhaesajsanguan, S., 2001, THE RELATIONSHIPS AMONG

ORGANIZATIONAL CLIMATE, JOB SATISFACTION AND

ORGANIZATIONAL COMMITMENT IN THE THAI

TELECOMMUNICATION INDUSTRY. E-Leader Singapore Journal, 10, Pp: 1-15.

Candra, Putu Dodik Kartika dan I Gede Riana. 2017. PERAN KOMITMEN ORGANISASIONAL MEMEDIASI PENGARUH KEPUASAN KERJA TERHADAP TURNOVER INTENTION. E-Jurnal Manajemen Unud, 6(10), Pp: 5287-5318.

Hayes, B., Bonner, A., \& Pryor, J. (2010, October). FACTORS

CONTRIBUTING TO NURSE JOB SATISFACTION IN THE ACUTE

HOSPITAL SETTING: A review of recent literature. Journal of Nursing

Management, Vol. 18, pp. 804-814. https://doi.org/10.1111/j.1365-

2834.2010.01131.x

Idrus, M., 2006. Implikasi Iklim Organisasi Terhadap Kepuasan Kerja Dan

Kualitas Kehidupan Kerja Karyawan. Jurnal Psikologi Undip, 3(1), Pp: 94106

Intan, K., Kusuma, P., \& Mujiati, N. W. (2017). PENGARUH PERCEIVED ORGANIZATIONAL SUPPORT DAN KOMITMEN ORGANISASIONAL TERHADAP TURNOVER INTENTION KARYAWAN DI HOTEL ALILA UBUD. 6(10), 5748-5774.

Kartika, E.W. dan Kaihatu, T.S., 2010. Analisis Pengaruh Motivasi Kerja Terhadap Kepuasan Kerja (Studi Kasus Pada Karyawan Restoran Di Pakuwon Food Festival Surabaya). Jurnal Manajemen Dan Kewirausahaan (Journal Of Management And Entrepreneurship), 12(1), Pp: 100.

Khan, Ayaz, 2006. Performance Appraisal's Relation With Productivity And Job Satisfaction. Journal Of Managerial Sciences, 1(2), Pp: 100-114.

Khan, Hafiz Ghufran A., 2014. Impact Of Reward System On Job Satisfaction Through Organizational Commitment: A Study Of Private Banks Based In Islamabad Pakistan. Economic And Social Development: Book Of Proceedings, Pp: 499-506.

Kurniasari, D. dan Halim, A., 2013. Pengaruh Lingkungan Kerja Dan Iklim Organisasi Terhadap Komitmen Organisasi Melalui Kepuasan Kerja Karyawan Pada Dinas Pasar Unit Pasar Tanjung Kabupaten Jember. Jurnal Ilmu Ekonomi, 8(2), Pp: 273-284.

Liana, Yuyuk, 2012. Iklim Organisasi dan Motivasi Berprestasi Terhadap Kepuasan Kerja dan Kinerja Guru, Jurnal Manajemen dan Akuntansi, 1 (2), Pp: 15-30.

Lina, Dewi, 2014. Analisis Pengaruh Kepemimpinan dan Budaya Organisasi terhadap Kinerja Pegawai dengan Sistem Reward sebagai Variabel Moderating, Jurnal Riset Akuntansi dan Bisnis, 14(1), Pp. 73-97

Made, N., \& Puspitawati, D. (2014). PENGARUH KEPUASAN KERJA TERHADAP KOMITMEN ORGANISASIONAL DAN KUALITAS LAYANAN. In Jurnal Manajemen Strategi Bisnis dan Kewirausahaan (Vol. 8). 
Mathis, Robert L., John H. Jackson. 2001. Manajemen Sumber Daya Manusia. Jakarta: Salemba Empat.

Meyer, John P. Herscovith L. 2001. Commitment in the workplace : toward general model, Human Resource Management Review, Vol. 11, Pp: 299-326.

Naderi Anari, Nahid. 2011. Teachers: Emotional Intelligence, Job Satisfaction, and Organizational Commitment, 24(4), Pp: 256-269.

Nita Asriani, Ni Wayan dan I Wayan Gede Supartha, 2017. Komitmen Organisasional Karyawan Dipengaruhi Oleh Iklim Organisasi Dan Kepuasan Kerja Pada Grand Sinar Indah Hotel. E-Jurnal Manajemen Unud, 6(11), Pp: 5999-6028.

Noordin, 2., Omar, S., Sehan, S. dan Idrus, S., 2010. Organizational Climate And Its Influence On Organizational Commitment. The International Business \&Economics Research Journal, 9(2), Pp: 1-10.

Rahmawati, S. dan I Wayan Gede Supartha, 2015. Pengaruh Iklim Organisasi Dan Motivasi Kerja Pada Kepuasan Kerja Pegawai Balai Wilayah Sungai BaliPenida. E-Jurnal Manajemen Universitas Udayana, 4(11), Pp: 3405-3437.

Sadhana, I Made. dan Sintaasih, D.K., 2015. Pengaruh Kepemimpinan Dan Kompensasi Finansial Terhadap Kepuasan Kerja Dan Kinerja Karyawan Ubud Aura Accomodation Di Ubud, Gianyar. E-Jurnal Manajemen Universitas Udayana, 4(1), Pp: 171-191.

Sari, E., 2009. Pengaruh Kompensasi Dan Iklim Organisasi Terhadap Kepuasan Kerja. Bisnis \&Birokrasi Journal, 16(1), Pp: 18-24

Sugiyono. 2014. Metode Penelitian Pendidikan Pendekatan Kuantitatif, Kualitatif Dan $R \& D$. Bandung: Alfabeta.

Suryanatha, A. A. N. B., \& Ardana, K. (2014). PENGARUH KEPEMIMPINAN TRANSFORMASIONAL DAN KOMITMEN ORGANISASI TERHADAP KEPUASAN KERJA KARYAWAN DAN ORGANIZATIONAL CITIZENSHIP BEHAVIOR (OCB) PADA BALEKA RESORT HOTEL \& SPA LEGIAN.

Susanty, Ety, 2013. Pengaruh Iklim Organisasi Terhadap Kepuasan Kerja Dan Komitmen Karyawan Pada Universitas Terbuka. Jurnal Organisasi Dan Manajemen, 8(2), Pp:121-134.

Syah, Harits, 2013. Pengaruh Kompensasi Finansial Terhadap Kepuasan Kerja Dan Motivasi Kerja Karyawan Pada PT. Graha Raja Empat. Jurnal Ilmu Manajemen, 1(2), Pp: 462-471.

Teck-Hong, T., \& Waheed, A. (2011). HERZBERG'S MOTIVATIONHYGIENE THEORY AND JOB SATISFACTION IN THE MALAYSIAN RETAIL SECTOR: THE MEDIATING EFFECT OF LOVE OF MONEY. In Asian Academy of Management Journal (Vol. 16).

Tommy S Suyasa, P. Y., Coawanta Dosen Fakultas Psikologi Universitas Tarumanaga, J. A., \& Mahasiswa Fakultas Psikologi Universatas Tarumanagara, J. (2004). SIKAP TERHADAP BUDAYA ORGANISASI DAN KOMITMEN ORGANISASI (Vol. 2).

Widiarti, N.L.P.D. dan Dewi, A.A., 2016. Pengaruh Iklim Organisasi Dan Kepuasan Kerja Terhadap Komitmen Organisasional Pada Dinas Pendapatan Provinsi Bali. E-Jurnal Manajemen Universitas Udayana, 5(10), Pp: 6345-6372. 
I Kadek Mahendra, dan Made Subudi. Pengaruh Iklim Organisasi dan Sistem Reward....

Widodo, Suparno Eko. 2015. Manajemen Pengembangan Sumber Daya Manusia. Yogyakarta: PUSTAKA PELAJAR.

Yudhaningsih, N. M., Ketut Sintaasih, D., \& Gede Riana, I. (n.d.). HUBUNGAN SISTEM REWARD DENGAN KOMITMEN ORGANISASIONAL DAN PENGARUHNYA TERHADAP KINERJA ( Studi Pada Bank Perkreditan Rakyat di Kabupaten Gianyar ). 2017. Retrieved from http://www.ojk.go.id 